\title{
Review
}

\section{Chemoprevention of colorectal cancer}

\begin{abstract}
Summary
Colorectal cancer is the fourth commonest form of cancer in men with 678000 estimated new cases per year worldwide, representing $8.9 \%$ of all new cancers. The disease is most frequent in Occidental countries and particularly so in North America, Australia, New Zealand, and parts of Europe. Prospects for colorectal cancer control are bright and a number of possible approaches could prove fruitful. Among these, pharmaceutical measures seem to be valid and logical approaches to the prevention of colorectal cancer and diminishing its impact. Such approaches could concentrate in primary prevention in at-risk subjects or be applied in altering the course of precursor or established disease. Treatments used must fulfil basic requirements of biological plausibility and safety in continued use in large numbers of subjects. Those available include vitamins and minerals, and other drugs with potential as antioxidants, immune modulators or promoters of cell differentiation or apoptosis. Of the various regimens suggested, vitamin A supplementation may even predispose to adverse outcomes, and antioxidant vitamins in general have no coherent body of evidence to support their use. $\mathrm{N}$-acetylcysteine and ursodeoxycholic acid have promising characteristics but there are as yet no clinical data to support the use of the former in gut epithelial cancer, and formal dose ranging studies must be carried out before the latter is submitted to large scale trial. Folate shows promising characteristics but non-steroidal anti-inflammatory drugs and vitamin D seem the most promising agents. Both seem to reduce the incidence of disease, and to reduce growth rates and/or induce differentiation or apoptosis in gut epithelial cancer cells. Both are also well understood pharmacologically. They may be preferred to newer selective compounds in the same class until these newer compounds are confirmed as safe for widespread long term use.
\end{abstract}

\section{Introduction}

Colorectal cancer is the fourth commonest form of cancer worldwide with an estimated 678000 new cases diagnosed in 1985. ${ }^{1}$ High incidence rates are found in Western Europe, North America and Australasia, intermediate rates in Eastern Europe with the lowest rates found in sub-Saharal Africa. ${ }^{2}$ In the United Kingdom there are some 25000 to 30000 new cases each year. The disease is not uniformly fatal, although there are large differences in survival according to stage of disease. It is estimated that there are, however, still nearly 400000 deaths from colorectal cancer worldwide annually. ${ }^{3}$

Current strategies for colorectal cancer control have concentrated upon early detection, either as screening tests for faecal occult blood (such as haemoccult testing), or more recently by endoscopy, and are essentially directed at preventing progression of the polyp-cancer sequence, or at the detection of cancer before invasion and metastasis have occurred. Alternative strategies are required, aimed at primary or secondary prevention, and which are widely applicable. One route would be the refinement of molecular screening methods designed to focus attention upon individuals who seem to be inherently at high risk by reason of their genetic make up. However, we are at present ill-placed to apply such methods to the common sporadic variety of colorectal cancer. Moreover, the method would still concentrate upon early detection in susceptible people rather than upon general prevention of disease, or alteration of its course once ordinarily diagnosed.

In these circumstances it makes sense to consider whether direct preventive measures could be applied and, given the large costs, complexities and duration of study, what would be likely to be the most fruitful methods. This article reviews evidence on the value of a range of potential chemotherapeutic agents.

Methods to be considered include general population intervention, polyp and cancer prevention in at-risk subjects, and trials in patients treated for cancer, an area which could be described as adjuvant chemoprevention where a treatment is given not primarily to treat the tumour but to prevent or slow down the development of local recurrences, metastases or second primary tumours.

\section{Choice of agent}

Any agents chosen for study should be capable of long term administration and should be largely if not completely free of adverse effects. In addition, there should be plausible epidemiological and/or biological evidence in favour of ability to inhibit polyp development and/or retard tumour growth. Finally, it should be possible to combine their use with that of antimitotic drugs so that a single trial could consider adjuvant therapy as well as adjuvant chemoprevention. The requirement of adverse effect free treatment which can be given continuously for very prolonged periods makes novel chemical entities unpromising candidates for immediate widespread use.

General preventative measures which could be applied essentially divide into lifestyle alterations and direct chemopreventative treatments. Lifestyle alterations directed at, for instance, reducing saturated fat intake have obvious logic and appeal given the demonstrable relation between fat intake and large bowel cancer incidence, and the general public health benefits. However, evidence from studies of cardiovascular disease illustrates the difficulty of devising dietary advice schedules to which people are likely to adhere, and which could be applied in large simple trials.

There is obvious logic therefore in considering chemopreventative measures provided attractive candidate treatments exist. This review concentrates upon pharmaceutical measures because their simplicity makes them easier to apply than broad dietary measures such as increasing fruit and vegetable intake. In this context, measures designed to inhibit vascularisation of tumours are not considered in this review.

Candidates include, at least, vitamin $\mathrm{A}$ or $\beta$ carotene, vitamin $\mathrm{C}$, vitamin $\mathrm{D}$, vitamin $\mathrm{E}$, calcium supplements, folate and anti-inflammatory drugs and $\mathrm{H}_{2}$ antagonists. Relatively novel chemical entities such as protease inhibitors are at an earlier stage making prolonged treatment too speculative a possibility. Taken overall there are suggestions of benefit for all of the above compounds, some stronger than others, in reducing the risk of developing colorectal cancer, and/or in preventing polyp occurrence. Effects on secondary spread are little understood except that anti-inflammatory agents have been used clinically in the past in trying to inhibit osteolysis. 
Table 1 Risks of colorectal cancer in relation to aspirin or NSAID use

\begin{tabular}{|c|c|c|c|}
\hline & $\begin{array}{l}\text { Odds } \\
\text { ratio }\end{array}$ & $95 \% C I$ & Dose/duration \\
\hline \multicolumn{4}{|l|}{ Aspirin } \\
\hline \multirow{2}{*}{ Peleg and coworkers ${ }^{4}$} & 0.08 & $0.01-0.59$ & $>624$ days any dose \\
\hline & 0.52 & $0.30-0.91$ & $<208$ days any dose \\
\hline \multirow[t]{2}{*}{ Rosenberg and coworkers ${ }^{5}$} & 0.5 & $0.4-0.8$ & $\begin{array}{l}1 \text { year or more any } \\
\text { dose }\end{array}$ \\
\hline & 0.5 & $0.2-0.9$ & $<1$ year any dose \\
\hline Kune and coworkers ${ }^{6}$ & 0.53 & $0.40-0.71$ & Any dose or duration \\
\hline \multirow[t]{3}{*}{ Giovannucci and coworkers ${ }^{7}$} & 0.09 & $0.02-0.43$ & Over 5 years ${ }^{\star}$ \\
\hline & 0.23 & $0.09-0.54$ & Over 3 years $\dagger$ \\
\hline & 0.52 & $0.32-0.84$ & In 1 yearł \\
\hline $\begin{array}{l}\text { Logan and coworkers } \\
\text { (adenomas) }\end{array}$ & 0.72 & $0.4-1.3$ & Any use \\
\hline \multicolumn{4}{|l|}{ Non-aspirin NSAID } \\
\hline \multirow[t]{2}{*}{ Peleg and coworkers ${ }^{4}$} & 0.34 & $0.15-0.77$ & >350 days \\
\hline & 0.77 & $0.48-1.23$ & $<350$ days \\
\hline $\begin{array}{l}\text { Kune and coworkers }{ }^{6} \\
\text { Aspirin or non-aspirin NSAID }\end{array}$ & 0.77 & $0.60-1.01$ & Any use \\
\hline $\begin{array}{l}\text { Logan and coworkers }{ }^{8} \\
\text { (adenomas) }\end{array}$ & 0.72 & $0.3-1.6$ & Prescribed use \\
\hline
\end{tabular}

^Affirmative responses to questionnaires two years apart on three occasions. †Affirmative responses to questionnaires two years apart on two occasions. $\ddagger$ Affirmative responses to a single questionnaire.

$\mathrm{CI}$, confidence interval.

There are also extensive animal or observational studies on a range of other compounds which includes the ornithine decarboxylase inhibitor difluoromethyl ornithine, flavonoids, dithiolethionine inducing glutathione transferase activity, selenium, and others.

\section{Use of anti-inflammatory agents}

There is abundant evidence that the use of non-steroidal anti-inflammatory drugs (NSAIDs) is associated with reduced risks of colorectal cancer and adenomatous polyps. $^{4-8}$ Effects have been demonstrated consistently, though not completely uniformly, are evident in casecontrol and cohort studies, and seem to be dose and duration of treatment related (table 1). Effects are biologically plausible because NSAID use seems to prevent or reduce the frequency of carcinogen induced animal colonic tumours, ${ }^{56}$ because NSAIDs seem to reduce growth rates in colon cancer cell lines, and because polyp formation in familial adenomatous polyposis coli (APC) seems to be retarded. ${ }^{11}{ }^{12}$

NSAIDs could act by switching off mitogenic stimuli, by inducing differentiation, or apoptosis or through enhancing immune surveillance. Clear evidence to support a particular mechanism as being of dominant importance is lacking. However, the most obvious mechanism is through inhibition of cyclo-oxygenase (COX). COX activity, particularly $\mathrm{COX}-2$, is upregulated in colorectal cancers but is less easily detectable in colorectal adenomas or in normal colonic epithelium. Further strong evidence for the significance of COX-2 expression comes from studies of the MIN mouse, which carries the APC gene, and develops multiple intestinal adenomata spontaneously. If animals with the mutation are crossbred with others with a disrupted COX-2 gene then it can be shown that effects on the induction of COX-2 activity are associated with altered rates of adenoma formation. Administration of the NSAID piroxicam to MIN mice reduces adenoma development, as might be expected. The relevance of APC gene studies to the common variety of colon cancer is emphasised by evidence that APC mutations are commonly detected in colonic carcinomata. ${ }^{13-18}$

There is also good evidence to suggest that induction of apoptosis is important, effects being demonstrable in cell lines and in familial adenomatous polyps. ${ }^{19-21}$ A possible link with COX inhibition derives from data indicating that COX-2 activity affects the occurrence of apoptosis in rat intestinal epithelial cells. ${ }^{22}$ The apparent simplicity of these inter-relations is, however, disturbed by results indicating that sulindac sulphone, which is not a significant inhibitor of COX, as well as the sulphide, a conventional NSAID, are both effective suppressants of growth in tumour cell lines. ${ }^{23}$

Furthermore, the aspirin metabolite salicylate, which is not a prominent COX inhibitor, seems to induce apoptosis in transformed colonic cell lines. Sensitivity seems to be increased in the later stages of neoplastic progression. ${ }^{23}$

Taken overall, the evidence indicates that NSAIDs are effective suppressants of tumour cell proliferation, can prevent or reduce the occurrence of experimentally induced colonic epithelial tumours, and that in humans use of NSAIDs for other therapeutic purposes reduces the frequency of colorectal cancer. Cases can therefore be made for considering NSAIDs in preventing cancer development, or in altering the behaviour of diagnosed disease as adjuvant therapy in preventing or retarding recurrent disease. Use of conventional NSAIDs is attractive because they have been licensed for human treatment for many years and their effects, outside cancer, are well understood. Newly developed COX-2 inhibitors are inherently attractive because their selectivity could prevent the well known upper gastrointestinal adverse effects of conventional NSAIDs. However, if COX inhibitors were to be used in preventing or altering the behaviour of colorectal cancer then it is likely that treatment would have to be given for many years. Furthermore, the expectation might be of modest alterations in disease behaviour so that benefits of treatment would be limited to a small proportion of individuals. In these circumstances it is doubtful whether a newly developed COX inhibitor could be used until its clinical pharmacological profile and pattern of adverse responses were well characterised.

Outside primary prevention of colorectal cancer, where trials in subjects at high risk seem attractive, there is a good case for treating those with diagnosed disease who are at risk of poor outcomes through worsening of existing disease or recurrence.

\section{Choice of drug}

Use of sulindac is supported by its effects in retarding adenoma development in familial adenomatous polyposis ${ }^{12}$ (though maybe not in sporadic disease ${ }^{24}$ ), and by data showing that it can induce apoptosis-although this is likely to be a class effect.

Indomethacin or other COX inhibitors have been suggested to improve natural killer cell activity, and to enhance non-specific immunotherapy of experimental lung tumour metastases. ${ }^{25-27}$ In a randomised study of cervical cancer in 160 patients, use of indomethacin improved survival of those given radiation treatment by $27 \%$ at five years and $41 \%$ at 10 years. ${ }^{28}$ Other studies in colorectal cancer do not seem to have been undertaken. Salicylate as sodium salicylate would be an interesting alternative, but it is unclear if it would have any therapeutic advantages, and dosage could be limited and compliance reduced by symptoms of salicism, vertigo, tinnitus, and deafness. Conventional NSAIDs would therefore probably be preferable to simple salicylate.

NSAIDs have class adverse effects on the kidney (interstitial nephritis), skin (rash and photosensitivity), lung (predispose to asthma), and liver (hepatitis-particularly with diclofenac). However, none of these, individually or collectively, is as frequent as gastrointestinal bleeding from peptic ulcers and, to a lesser extent, from the colon. Risks vary up to 20 -fold between agents and by up to 10 -fold by dose (table 2). ${ }^{29}$

There is no obvious way in which risks of gastrointestinal adverse effects can be prevented, except by reducing doses 
Table 2 Risks of peptic ulcer bleeding in subjects taking commonly used non-aspirin NSAIDs for at least three months, ${ }^{29}$ and in individuals taking prophylactic aspirin at least five times a week for the past $t^{39}$

\begin{tabular}{lll}
\hline & Odds ratio & $95 \% C I$ \\
\hline Piroxicam & 18.0 & $7.2-45.0$ \\
Indomethacin & 12.8 & $5.4-30.5$ \\
Naproxen & 5.8 & $3.0-11.4$ \\
Diclofenac & 3.6 & $1.8-7.2$ \\
Ibuprofen & 1.1 & $0.6-1.9$ \\
Aspirin & & \\
$\quad 300$ mg daily & 3.9 & $2.5-6.3$ \\
150 mg daily & 3.2 & $1.7-6.5$ \\
75 mg daily & 2.3 & $1.2-4.4$ \\
\hline
\end{tabular}

${ }^{\star}$ Compared with controls.

$\mathrm{CI}$, confidence interval.

or by giving concurrent antisecretory or gastroprotective treatments. The use of misoprostol as a gastroduedenal protective drug ${ }^{30}$ would seem to be unwise because deliberate addition of prostaglandin could perhaps interfere with the antagonist and possibly the desired therapeutic effects of an NSAID. The addition of histamine $\mathrm{H}_{2}$ antagonists might be expected to reduce, depending on dose and choice, the frequency of gastric and duodenal ulcer $^{3132}$ and possibly the rate of ulcer complications, though this is unproved. Use of a proton pump inhibitor might be more beneficial through more powerful antisecretory effects but with the theoretical possibility of adverse tumour responses through raised serum gastrin concentrations, although these have been disputed..$^{33-35} \mathrm{~A}$ more important practical disadvantage of antisecretory therapy would be through addition of an extra treatment, so reducing the likelihood of overall compliance.

If epidemiological findings of possible preventative actions are a fair guide then available evidence (table 1) suggests that aspirin may, if anything, be more effective in preventing disease and so perhaps, if the further extrapolation is fair, in modulating existing disease behaviour. However, it should be noted that experimental and clinical evidence largely relates to non-aspirin NSAIDs.

Epidemiological evidence gives limited guidance on what doses of aspirin might be used deliberately to prevent colorectal cancer occurrence because retrospective enquiry is likely to be a poor method of determining what doses patients habitually took many years before. Prospectively obtained data in the Nurses Health Study indicated that $10-15$ years is required to see an effect. ${ }^{36}$ The US physicians study, which suggested that $325 \mathrm{mg}$ aspirin on alternate days might be relatively ineffective is not incompatible in findings because its time span (seven years) was shorter. ${ }^{37}$ Doses of $325 \mathrm{mg}$ daily, which would raise the risk of ulcer bleeding by about fourfold (table 2), would seem necessary therefore in prevention and maybe also, if extrapolation is justified, in adjuvant treatment of established disease. Aspirin has additional potential cardiovascular benefits through inhibiting platelet COX, although similar benefits might be obtainable with-for example, regular indomethacin use. Note here that colon cancer incidence rates tend to be particularly raised in countries with high mortality rates from cardiovascular disease so that the potential for added benefit may be greater than expected.

Enteric coated aspirin has two possible advantages. It might deliver aspirin direct to the colon and it might reduce the risk of upper gastrointestinal adverse effects. Both advantages seem doubtful. Firstly, enteric coated drug is likely to be largely if not completely absorbed in the small bowel and, secondly, current evidence suggests that enteric coating may not greatly, or at all reduce the risk of ulcer complications. $^{38} 39$

The selective COX inhibitors may ultimately prove to have a place, but judgment must be deferred until their pharmacological profiles and long term effects, good and not so good, are better understood.

\section{Vitamin A or betacarotene and retinoids}

Retinoids and retinoid related molecules show promise as chemotherapeutic or preventative agents because they can induce differentiation and apoptosis, the differentiating effects being well demonstrated in myeloid cells. ${ }^{40}{ }^{41}$

Interpretation of evidence is complicated because the generic term vitamin $\mathrm{A}$ can be used to refer to the preretinoid betacarotene and to retinol. Furthermore, the retinoids include compounds, such as all trans and 9 cis retinoic acid, which are clearly mutagenic, which limits therapeutic value. Complications are reinforced by evidence that retinoids can have notably dissimilar effects experimentally according to the system in use. Thus 9 cis retinoic acid can either enhance or inhibit the effects of 1,25 dihydroxy vitamin $\mathrm{D}$ in retarding colon cancer cell line growth. ${ }^{42}$ Differences between retinoids will depend greatly on variable activation of retinoic acid (RAR) and retinoid X (RXR) receptors. ${ }^{43}$

Low serum betacarotene concentrations have been noted to be associated with later liability to all cancer, particularly lung cancer and also stomach, but not colon, cancer. ${ }^{44}$ Antioxidant vitamins (betacarotene and C, or A, $\mathrm{C}$ and $\mathrm{E}$ ) were however found elsewhere to be protective against rectal cell proliferation in patients with rectal adenomas $^{45} 46$ and in the prevention of recurrence of adenomas. ${ }^{47}$

By contrast, although a contemporaneous study of micronutrient intake suggested protection associated with intake of betacarotene, ascorbic acid, vitamin $\mathrm{E}$, and folate, ${ }^{48}$ a review of five dietary studies showed unconvincing evidence of protection against colon cancer by vitamin A. ${ }^{49}$ Furthermore, a large (three times as large as the positive report ${ }^{47}$ ) study of prevention of adenoma recurrence using betacarotene $25 \mathrm{mg}$ daily, instead of vitamin A 30000 IU daily, together with vitamins $C$ and $E$ showed no evidence of protection (see figures below under vitamin C). ${ }^{50}$ Pure retinoids may ultimately prove to be of interest if consistent inhibitory effects on human colon cancers can be shown, and if their safe use is demonstrable.

Three large, randomised intervention studies of betacarotene have now produced results which were consistent with either no effect or a deleterious effect on lung cancer risk. ${ }^{51-53}$ Taken overall, the evidence to support use of vitamin A or betacarotene in the prevention of colorectal cancer or modulation of its behaviour is weak with indications, if anything, of possible harm in other pathology.

Other retinoids being explored include 13 cis retinoic acid and 4 hydroxyphenretinamide. ${ }^{54}{ }^{55}$ In general all compounds present potential problems because of adverse responses. Those for isotretinoin, an isomer of tretinoin, include corneal opacities, cataracts, convulsions, myalgia, thrombocytopenia, and neutropenia as well as fetal malformations. There is, however, reasonable prospect of obtaining retinoid molecules which increase differentiation and/or induce apoptosis because synthetic molecules can be constructed which activate limited parts of the complex retinoid response network. At least in myeloid cells retinoic acid and anti-inflammatory agents can act on a single intracellular target site. ${ }^{56}$

\section{Vitamin C}

Generally dietary studies have suggested that high fat intake is associated with increased risk of colon cancer and that consumption of fruit, vegetables and fibre might be protective. Reduced risk of colon cancer has been associated with the use of vitamin $C,{ }^{48}$ and vitamin $\mathrm{C}$ combined with vitamin A seemed to reduce crypt cell proliferation rates in humans 
measured by the bromodeoxyuridine technique. Similar effects were noted with a diet supplemented with vitamins A, $\mathrm{C}$ and $\mathrm{E}$ when using the tritiated thymidine technique. ${ }^{45}{ }^{46}$ Finally, protection against polyp formation using vitamin C alone was noted in one study of familial polyposis. ${ }^{57}$

The assumption has been of an anti-oxidant mechanism. Vitamin C as part of such a regimen (vitamin A 30000 IU daily, vitamin C $1 \mathrm{~g}$ daily and vitamin E $70 \mathrm{mg}$ daily) appeared to be protective in a study of 255 patients with polyps randomised to three treatment arms (vitamins, lactulose or placebo). Recurrence rates in the 209 evaluable subjects were $5.7,14.7$ and $35.9 \%$ respectively. ${ }^{47}$ By contrast, another much larger study included 864 patients with 751 completing one to four years' treatment. In the 751 completing treatment $36 \%$ developed polyps. There was no advantage to combined vitamin treatment (relative risk 1.08, $95 \%$ confidence interval (CI) 0.91 to 1.29$).{ }^{50}$ Two other studies, of vitamins $\mathrm{C}$ and $\mathrm{E}$ combined, one of recurrence of familial polyposis, and the other of 143 patients for recurrence of simple polyps gave negative results. ${ }^{58} 59$

The evidence favouring vitamin $\mathrm{C}$ and/or anti-oxidant therapy in general is not strong, the results from the single large polyp study being particularly unfavourable.

\section{Vitamin D}

This vitamin in its activated dihydroxy form plays a central role in cell differentiation. People with low intake of vitamin $\mathrm{D}$ or with low serum concentrations have been noted by some to be at increased risk of colon cancer, ${ }^{6061}$ and in North America, albeit from an inherently weak study design, an inverse correlation between sunlight exposure and liability to colon cancer has been described. ${ }^{62}$ Animal studies also suggest protective effects against experimental (e.g. 1-2 dimethyl hydrazine induced) colon carcinogenesis. ${ }^{63}{ }^{64} 1,25$ dihydroxy vitamin D3 (OH D3) at concentrations of $10^{-10}$ molar inhibits multiplication within colon cancer cell lines and induces maturation. Functional vitamin $\mathrm{D}$ receptors are consistently demonstrable in human colorectal neoplasms, ${ }^{65}$ and human tumour xenograft growth is slowed by treatment with $\mathrm{OH} \mathrm{D} 3{ }^{66}$

The effects of OH D3 on cell differentiation seem likely to be mediated by a non-genomic cell membrane pathway. ${ }^{67}$ Thus protein kinase C (PKC), which plays a critical part in signal transduction within cells in the control of differentiation and growth, seems to be directly activated by $\mathrm{OH} \mathrm{D} 3$. In this context it is noteworthy that at least one isoform, $\mathrm{PKCe}$, which is calcium independent, is activated by $\mathrm{OH} \mathrm{D} 3$ and $\mathrm{OH} \mathrm{D} 3$ effects on cell differentiation can be mimicked by a non-hypercalcaemic analogue, ${ }^{6869}$ and a non-calcaemic analogue inhibits azoxymethane induced colonic tumorigenesis, possibly at an initiation stage through effects on $\mathrm{K}$-ras mutations. ${ }^{70}$

Evidence is not entirely one-sided. Thus two dietary studies showed weak evidence of protection, the one suggesting benefit from supplements but not from dietary vitamin D, and the other a non-significant odds ratio $(0.73,95 \% \mathrm{CI}$ 0.45 to 1.18$),{ }^{71}{ }^{72}$ compatible nevertheless with useful effects not clearly demonstrable in a study lacking power.

Taken overall, the evidence is reasonably in favour of vitamin $\mathrm{D}$ having useful antitumour activity, but there is a lack of clinical data in support. This is likely to be because vitamin $\mathrm{D}$ has well known adverse effects of hypercalcaemia which may have been a limitation to its past consideration. The use of modest doses, while ensuring that milk or calcium intake are not high, would however seem safe. Clues to the likely safe levels could be obtained from studies of vitamin D treatment in the elderly. ${ }^{73}$ As with COX inhibitors there is evidence, if somewhat less strong, of actions in preventing tumour occurrence and in altering the behaviour of established disease, but possible interrelations do not seem to have been studied.

The attractions of the selective COX-2 inhibitors are mirrored by those of the non-hypercalcaemic analogues of vitamin $\mathrm{D}$ as promising preventative or adjuvant treatments once long term safety is confirmed.

\section{Calcium}

Calcium was proposed on theoretical grounds as having a potential role in preventing colorectal carcinogenesis through reducing bile acid concentrations in the bowel. Effects in reducing cell proliferation have been detected in human studies and in animals, but have been denied by others. ${ }^{74} 75$ Whether any actions in fact arise through inactivating bile acids rather than through the vitamin $\mathrm{D}$ pathway is unclear. A better case can probably be made for vitamin D itself.

\section{Vitamin E}

Findings in five studies independently suggested nonsignificant trends towards reduced blood concentrations of $\alpha$-tocopherol in subjects subsequently developing colorectal cancer compared with controls. Combination of the data showed a barely significant change in odds ratio 0.6 (95\% CI 0.4 to 1.0 ) for the highest quartile of serum concentration compared with the lowest, but reduced to 0.7 (95\% CI 0.4 to 1.1 ) when allowance was made for serum cholesterol concentrations. ${ }^{76}$ Other data (Iowa Women's Health Study) suggested a highly significant inverse trend between serum concentration and cancer risk ( $p$ for trend $<0.001) .{ }^{77}$ A third study suggested protection from vitamin $\mathrm{E}$ as well as folate, ascorbate or betacarotene. ${ }^{48}$

Use of vitamin $\mathrm{E}$ has the advantage that it is, for all practical purposes, safe. A mechanism of action is unclear beyond enhancement of anti-oxidant concentrations, the value of which is unclear. However, such a regimen failed to reduce adenoma incidence (when given with ascorbic acid and betacaroten ${ }^{50}$ ) although another smaller studysee vitamin C section-using $70 \mathrm{mg}$ daily with vitamins $\mathrm{C}$ and $\mathrm{A}$, suggested highly significant protection. ${ }^{47}$

\section{Folate}

Dietary case-control comparisons show protection from colon cancer associated with the consumption of fruit and vegetables, and after adjustment for other factors, folate emerges as potentially protective. ${ }^{78-80}$ Support comes from experimental tumour studies, with folate depletion increasing the yield and repletion diminishing the yield. ${ }^{81}{ }^{81 a}$ DNA hypomethylation occurs in colonic tumours, and lack of folate reduces methyl group availability for DNA methylation which itself is associated with gene silencing. ${ }^{82}$ Studies indicating raised risks of colon cancer or adenoma in association with alcohol intake ${ }^{78}$ 82a are consistent because demand for folate is raised by alcohol consumption. In ulcerative colitis the risk of dysplasia also seems to be reduced in those with higher levels of red cell folate. ${ }^{83}$ Studies of folate are reasonably consistent in indicating benefit. A basis in supplying methyl groups to convert homocysteine to methionine and then for DNA methylation via S-adenosylmethionine ${ }^{83 a}$ is logical. However, if this is true it is unclear why evidence in support of methionine intake is not stronger, whereas protein intake, as least as red meat, seems if anything to be a risk factor.

\section{N-acetylcysteine}

This compound has come under consideration because of anti-oxidant properties, and because its use appears to reduce the frequency of experimentally induced lung and skin tumours. ${ }^{84}$ There are no studies of human gastrointestinal cancer treatment, but a large European 
study (Euroscan) using $\mathrm{N}$-acetylcysteine and/or retinol palmitate in a factorial design treating patients with resected oral, laryngeal or lung cancer is nearing completion. ${ }^{85}$

\section{Ursodeoxycholic acid}

Treatment with this, the 7-B-epimer of chenoeoxycholic acid, reduced the incidence of experimentally induced colon tumours in rats. Administration of ursodeoxycholic acid has also been shown notably to reduce the concentration of the secondary bile acid deoxycholic acid in the colon, while increasing that of lithocholic acid, although both have been considered to be promoters of colon cancer. ${ }^{86}{ }^{87}$ Whether anti-cancer effects are by this route or another, notably modulation of protein kinase $\mathrm{C}$ isoforms ${ }^{88}$ is unclear. Applicability in cancer prevention is uncertain, thus the dose required and the critical timing would have to be established.

\section{$H_{2}$ antagonists}

Although it was initially feared that $\mathrm{H}_{2}$ antagonist treatment would precipitate the occurrence of gastric cancer through allowing bacterial overgrowth in the stomach and conversion of dietary nitrate to nitrosamines, supportive evidence for this view has not emerged. On the contrary there is evidence that use of $\mathrm{H}_{2}$ antagonists can improve the course of gastric cancer, and some evidence that treatment is beneficial in colorectal cancer.

In a Danish study ${ }^{89} 181$ patients with gastric cancer were randomised to receive cimetidine $1 \mathrm{~g}$ daily or placebo. Life expectancy was prolonged by approximately a third (median survival 450 and 310 days respectively). In a second study ${ }^{90}$ of 64 patients with colorectal cancer initially randomised, with a mean follow up of 31 months survival was $96 \%$ and $100 \%(n=27$ and $n=7$ respectively) in treated patients with colon and rectal cancer, and $68 \%$ and $53 \%$ in the controls ( $n=19$ and $n=11$ respectively).

In a third small trial ${ }^{91}$ seven days of cimetidine treatment at the time of surgery was associated with a greater degree of tumour lymphocyte infiltration at surgery than controls ( $67 \%$ and $24 \%$ respectively $\mathrm{p}<0.01)$. Three year survival was $93 \%$ in cimetidine recipients $(n=14)$ and $59 \%$ in controls $(n=20)$.

Treatment has been claimed to improve host immunoreactivity by receptor antagonism of suppressor T cells. ${ }^{91}{ }^{92} \mathrm{It}$ is unclear whether there are equivalent or different immunomodulatory properties of other histamine $\mathrm{H}_{2}$ antagonists. On the one hand, metiamide (an $\mathrm{H}_{2}$ antagonist abandoned because it caused bone marrow suppression) and ranitidine were more effective in preventing growth in an animal tumour model of bowel cancer than cimetidine. ${ }^{94}$ On the other, immunomodulative effects on peripheral blood mononuclear cells were more obvious with cimetidine than with ranitidine or another $\mathrm{H}_{2}$ antagonist, famotidine. ${ }^{95}$

Examination of data obtained in a surveillance study of 10000 users of cimetidine followed for 10 years has shown no significant change in colon cancer death rates. ${ }^{96} \mathrm{~A}$ randomised clinical trial of cimetidine in 442 cases of gastric cancer has also shown no prolongation of survival, a result at variance with the earlier Danish study. ${ }^{97}$ Taken overall, data do not give good evidence to support benefit from $\mathrm{H}_{2}$ antagonists in gut epithelial cancer.

\section{Other compounds}

A range of other compounds has been extensively studied in animals or cell systems. They include alphadifluoromethylornithine, the dithol ethionine oltipraz, selenium and organoselenium compounds, the adrenal steroid dehydroepiandrosterone, novel retinoids, and flavonoids.
Alphadifluoromethylornithine interferes ${ }^{98} 99$ with putrescine formation by acting as an ornithine decarboxylase inhibitor and there is evidence that it modulates ras protooncogene formation. ${ }^{100}$ Clinically it causes dose related ototoxicity which is reversible, but which limits doses to below $0.5 \mathrm{~g} / \mathrm{m}^{2}{ }^{101}$ Given the long period for which chemopreventative treatment would have to be given, and the wide exposure of individuals who would never develop cancer, the risks may be unduly high.

Retinoids have important prodifferentiating properties but the risks of adverse effects are high because of non-selective actions. The dithiol ethionine oltipraz shows good evidence of chemopreventative properties in animals, the likely basis being increased glutathione transferase activity in tissues, leading to enhanced detoxification pathways. ${ }^{102} 103$ Dehydroepiandrosterone also reduces experimental animal tumour induction possibly through a non-specific adrenal steroid action, or possibly in some way associated with modulation of sex steroid receptors in the bowel epithelium. ${ }^{104}$

Reduced frequencies of bowel cancer or adenomata have been noted in those with relatively high but still normal blood or tissue selenium concentrations, ${ }^{105}$ and organoselenium compounds seem to be protective in animals. ${ }^{106}$ However, others have found no correlations between exposure and protection. ${ }^{107} 108$ The case for flavonoids is limited ${ }^{110}$ but interesting, as is that for other compounds such as resveratrol which is derived from red grapes. ${ }^{111}$

\section{Conclusions}

There are many indications of possible therapeutic benefits for a range of (at the present time mainly) vitamins and for anti-inflammatory agents. Data are undoubtedly strongest for the anti-inflammatory group.

There is a large body of epidemiological evidence suggesting that aspirin and non-aspirin NSAID use is associated with reduced risks of adenomatous polyp development and of cancer. In addition polyp formation in familial adenomatous disease, but perhaps not in sporadic disease, seems to be retarded by treatment with sulindac. Cancer induction by experimental carcinogens is also inhibited, cell growth rates are reduced and apoptosis induced. Although effects may be associated with COX, particularly COX-2 inhibition, there are suggestions that the mechanisms may be more complex because apoptosis can be induced by related substances which are not prominent COX inhibitors. Aspirin and the other NSAIDs are of particular interest because their actions seem to include prevention of cancer or adenoma occurrence, and interference with the behaviour of neoplastic tissues in vivo or in vitro.

If aspirin is used then doses of at least $325 \mathrm{mg}$ daily are likely to be needed, with full doses of non-aspirin NSAIDs as alternatives.

Trials of anti-oxidant vitamin regimens based on vitamins $\mathrm{A}, \mathrm{C}$ and $\mathrm{E}$ have given inconsistent results and such a regimen now seems unpromising. Use of retinoids alone will have to be viewed with caution in view of evidence that survival in lung cancer is adversely affected, and because at least one retinoid seems to interfere with beneficial actions of vitamin $\mathrm{D}$ in retarding cancer cell growth.

Vitamin D may be the next most promising substance for trial after the NSAIDs. There is epidemiological evidence suggesting that exposure to sunlight and raised serum concentrations reduce disease risk. There are experimental data to show that there are functional vitamin $\mathrm{D}$ receptors in human colon cancer cells, and growth of colon cancer cell lines appears to be inhibited by $\mathrm{OH}$ D3. Further exploration of these properties, which, like those of NSAIDs, seem to include prevention of disease occurrence and the potential to alter established disease behaviour, 
may have been inhibited by the risks of hypercalcaemia, although the epidemiological data relate to nonhypercalcaemic levels of $\mathrm{OH} D 3$ and the experimental data have been obtained with very low concentrations of $\mathrm{OH}$ D3. Use of new analogues which do not seem to cause hypercalcaemia is unlikely to be justified in preventative or adjuvant settings until side effect profiles are fully characterised and safety in long term use confirmed. Calcium salts probably offer no significant advantages.

Although there are other candidates, supportive evidence is generally limited. Folate is non-toxic, but supportive evidence to justify large scale trials is inadequate. Ursodeoxycholic acid shows promise of value in disease prevention, but the appropriate dose is unclear. $\mathrm{N}$-acetylcysteine is being included in regimens for head and neck cancer, and the outcome of these may help determine value. Histamine $\mathrm{H}_{2}$ antagonists have some limited but inconsistent evidence to favour their use.

Perhaps the most obvious chemopreventative method, at least in women, is that of oestrogen replacement. It has been known for many years that the sex ratio of colon cancer varies with age. Functional oestrogen receptors are present in the bowel epithelium ${ }^{112}$ and cancer risk is notably reduced in patients on oestrogen replacement therapy. ${ }^{113} 114$

\section{General population intervention}

There is currently no chemical intervention for colorectal cancer where sufficient evidence has been obtained in randomised clinical trials; on these classic grounds of evidence-based medicine it is not possible to advocate use of any compound for chemoprevention in a general population study. Furthermore, the annualised frequency of cancer or polyps is too low to make a randomised trial in unselected subjects an attractive proposition. Thus, suppose in an average European country at, say, the age of 55 the frequency of new cancers is of the order of 50 per 100000 per year. Then the randomisation of 200000 subjects with an agent in use with a putative reduction of risk of $30 \%$ would yield at the end of five years 250 cases in the control group of 100000 , and 180 cases in the test group. The difference is likely to be considerably smaller because of failures of compliance or outright dropout, and because a $30 \%$ reduction in risk would be a fairly large expectation. A further likely reduction of power would stem from the tendency to recruit individuals who, by reason of lifestyle, were already likely to be at reduced risk. It is important to bear in mind that the effective sample size drops off as the square of the non-compliance rate in the treatment group and the square of the self-medication rate among the control group the effects of these on the statistical power of a trial can be dramatic. ${ }^{115}$

It is well known that individuals with adenomata, particularly large adenomata, are at increased risk of second or subsequent polyps. Selective recruitment from such a population would have intrinsic attractions. Firstly, subsequent disease risk is raised and therefore the numbers requiring recruitment would be reduced. Secondly, the chances of patients adhering to treatment schedules would be likely to be raised because of their primary disease profiles. Data obtained in such a study would in essence be concentrated upon rates of adenoma development, with little emphasis upon cancer occurrence, and not upon cancer behaviour since few invasive cancers would be likely to be detected. Nevertheless, such a study has obvious attractions: colorectal polyps present one of the most useful intermediate end points (biomarkers) at the present time.

SECONDARY PREVENTION

Patients who have successful resections of primary colorectal neoplasms are known to be at risk of second, synchronous or metachronous cancers, and of synchro- nous or metachronous adenomata. Studies of these patients would therefore be able to consider polyp prevention, second cancer prevention, and prevention or delay of metastasis or suture line recurrence. Patients who have had apparently successful resections are likely to be well motivated to embrace preventive measures, and would therefore be expected to have high compliance rates. For all these reasons a combined study of adjuvant therapy and adjuvant chemoprevention has obvious attractions.

Data obtainable should include comparative information on mortality patterns - all causes and colon cancer; the occurrence of metachronous polyps, as all adenomata and as pathologically advanced lesions; the occurrence of metachronous colorectal cancer; and on co-morbidity.

MORTALITY

The overall five year survival of patients with colorectal cancer is of the order of $50-55 \%$, with deaths in the main being due to cancer spread. In advanced colorectal cancer, in which curative resection is possible, five year survival in Dukes' B is $45 \%$ and drops to $30 \%$ in Dukes' C. Five year survival in resected Dukes' $\mathrm{A}$ is around $80 \%$ and survival following simple resection of an adenomatous pedunculated polyp containing carcinoma in situ (or severe dysplasia) or intramucosal carcinoma is generally close to $100 \% .{ }^{116}$ Prospects of adequate follow up would be improved if an age cut off, say, of 75 years is applied.

All other causes of mortality will depend upon the age range recruited, but the chances of showing effects are small, except within overall cardiovascular mortality.

METACHRONOUS POLYPS

The occurrence rate can be estimated by taking the colonoscopic findings in investigations where polyp clearance has been considered complete at colonoscopy. Subsequent polyp occurrence rates in those who have had a primary large bowel cancer will probably be somewhat higher than in patients without initial overt cancer so that figures at the least, will not be likely to overestimate. Data from the United States National Polyp Study suggest a $3.3 \%$ rate over a three year period for all adenomata. ${ }^{117}$ That figure is reasonably close to the $3.6 \%$ annual rate recorded over five years by Greenberg et al in a trial of antioxidant vitamins. ${ }^{50}$

METACHRONOUS CANCER OF THE COLON

The rate has been estimated at $0.35 \%$ per year overall. ${ }^{118}$ Plainly numbers will be limited in the early years after resection of another primary cancer on the assumption that surgeons will routinely seek second primary tumours and adenomata at the time of initial curative surgery. Furthermore, the rate will be likely to be lower still in patients in surveillance programmes, as will be likely in those with resected cancers.

\section{OTHER RELEVANT CANCERS}

Breast and ovarian cancer have tended to occur in association with colorectal cancer within families, and there is evidence for common environmental factors. Although ovarian cancer is rare, breast cancer is common, and is roughly twice as common as colorectal cancer. A large preventative study on intestinal cancer might therefore be expected to accrue data on breast cancer. However, assuming a breast cancer incidence rate of 80 per 100000 per year then in a 1000 patient study of colorectal cancer in men and women the expected disease frequency would still be 0.4 cases per year or less than three cases over a six year period.

OVERALL DISEASE FREQUENCY

Table 3 shows some possible findings over a six year period. It can be seen that a secondary prevention study allows 
Table 3 Possible outcomes in terms of death from recurrent cancer and of diagnoses of new colonic polyps in 1000 patients having successful (clinically curative) colonic resections

\begin{tabular}{llllll}
\hline & & & & \multicolumn{2}{l}{ Developed colonic polyps } \\
\cline { 5 - 6 } $\begin{array}{l}\text { End of } \\
\text { year }\end{array}$ & $\begin{array}{l}\text { Still } \\
\text { alive }\end{array}$ & $\begin{array}{l}\text { Dead of } \\
\text { primary } \\
\text { disease }\end{array}$ & $\begin{array}{l}\text { Dead of } \\
\text { other } \\
\text { causes }\end{array}$ & $\begin{array}{l}\text { Pathologically } \\
\text { advanced }\end{array}$ & All adenomata \\
\hline 1 & 916 & 60 & 24 & - & - \\
2 & 840 & 55 & 21 & - & - \\
3 & 760 & 50 & 20 & 28 & - \\
4 & 693 & 45 & 18 & - & - \\
5 & 652 & 25 & 17 & - & 166 \\
6 & 631 & 15 & 16 & 22 & 381 \\
Total & & 250 & 116 & 50 &
\end{tabular}

Data assume (1) an overall death rate from recurrent cancer of $25 \%$ in six years, (2) a death rate from other causes of $2.5 \%$ per annum, and (3) a colonic polyp incidence rate of $3.3 \%$ at triennial screening for pathological advanced lesions and $25 \%$ for all adenomata.

examination of two major problems - the outlook for the initial disease and the prospects of preventing precursor lesions (adenomatous polyps). Treatment might also affect the overall chances of other disease but (outside cardiovascular disease) would be unlikely to show material differences for individual causes. Note that any substantial increase in expected death rates from colonic cancer would increase the chances of detecting treatment effects there, whereas any fall in death rates, overall and/or from cancer would increase the size of the group which could develop new adenomatous polyps. Table 3 emphasises the value of recruiting cancer cases of relatively good prognosis if enough are to survive to provide an evaluable cohort for the study of polyps of a pathologically advanced nature.

Study of patients with treated colorectal cancer has attractions though the potential to examine both an intermediate biomarker, development of new adenomata, and the occurrence of malignant spread from treated disease. Depending on the choice of agent and timing of its use there should be no interference with curative or adjuvant chemotherapy of the conventional type. Studies would also be conducted in patients with a high motivation to comply by reason of treated disease of the same type, and in a group where the risk of further malignancy of the same type, or of recurrent polyps, would be relatively high.

We conclude that there are good reasons for believing that the time is right for the conduct of randomised trials of relatively simple and comparatively non-toxic treatments with biological plausibility in colorectal cancer.

Support from the Associazione Italiana per lo Ricerca sul cancer, the Medical Research Council of the United Kingdom and the Special Trustees of the Former United Birmingham Hospitals is gratefully acknowledged.

M LANGMAN Department of Medicine, Queen Elizabeth Hospital, Birmingham B15 2TH, UK

P BOYLE

Division of Epidemiology and Biostatistics, European Institute of Oncology, via Ripamonti 435, 20141 Milan, Italy

1 Parkin DM, Pisani P, Ferlay J. Estimatesof the worldwide incidence of eighteen major cancers in 1985. Int $\mathcal{F}$ Cancer 1993;54:594-606.

2 Boyle P, Zaridze DG, Smans M. Descriptive epidemiology of colorectal cancer. Int f Cancer 1985;36:9-18.

3 Pisani P, Parkin DM, Ferlay J. Estimates of the worldwide mortality rate from 18 major cancers in 1985. Implications for prevention and projections of future burden. Int $\mathcal{F}$ Cancer 1993;55:891-903.

4 Peleg I, I Maibach HT, Brown SH, et al. Aspirin and non-steroidal anti-inflammatory drug use and the risk of subsequent colorectal cancer. Arch Intern Med 1994;154:394-9.

5 Rosenberg L, Palmer JR, Zauber AG, et al. A hypothesis: non-steroidal antiinflammatory drugs reduce the incidence of large bowel cancer. $\mathcal{F}$ Natl Cancer Inst 1991;83:355-8.

6 Kune GA, Kune S, Watson JF. Colorectal cancer risk, chronic illnesses, operations and medications: case control results from the Melbourne operations and medications: case control results from
Colorectal Cancer Study. Cancer Res 1988;48:4399-404.

7 Giovannucci E, Rimm EB, Stampfer MJ, et al. Aspirin use and the risk of colorectal cancer and adenoma in male health professionals. Ann Intern Med 1994;121:241-6.
8 Logan RF, Little J, Hawtin PG, et al. Effect of aspirin and non-steroidal anti-inflammatory drugs on colorectal adenomas: case control study of subjects participating in the Nottingham faecal occult blood screening prosubjects participating in the Not
gramme. $B M \mathcal{F} 1993 ; 307: 285-9$

9 Narisawa T, Sato M, Tani M, et al. Inhibition of development of methylnitrosourea induced colonic tumours by peroral administration of indomethacin. Gann 1982;73:377-81

10 Reddy BS, Rao CV, Rivenson A, et al. Inhibitory effect of aspirin on azoxymethane-induced colon carcinogenesis in F 344 rats. Carcinogenesis 1993;14:1493-7.

11 Labayle D, Fischer D, Vielh P, et al. Sulindac causes regression of rectal polyps in familial adenomatous polyposis. Gastroenterology 1991;101:635-9.

12 Giardiello FM, Hamilton SR, Krush AJ, et al. Treatment of colonic and rectal adenomas with sulindac in familial adenomatous polyposis. $N$ Engl f Med 1993;328:1313-16.

13 Kargman SL, O’Neill GP, Vickers PJ, et al. Expression of prostaglandin G/H synthase-1 and -2 protein in human colon cancer. Cancer Res 1995;55: 2556-9.

14 Gustafson-Svard C, Lilja I, Hallbook O, et al. Cyclo-oxygenase-1 and cyclooxygenase-2 gene expression in human colorectal adenocarcinomas and in azoxymethane induced colonic tumours in rats. Gut 1996;38:79-84.

15 Eberhart CE, Coffey RJ, Radhika A, et al. Upregulation of cyclo-oxygenase 2 gene expression in human colorectal adenomas and adenocarcinomas. Gastroenterology 1994;107:1183-8.

16 Oshima M, Dinchuk JG, Kargman S, et al. Suppression of intestinal polyposis Apc. D761 knock out mice by inhibition of cyclo oxygenase 2 (COX-2). Cell 1996;87:803-9.

17 Jacoby RF, Marshall DJ, Newton MA, et al. Chemoprevention of spontaneous intestinal adenomas in the Apc Min mouse model by the non-steroidal anti-inflammatory drug piroxicam. Cancer Res 1996;56:710-14.

18 Powell SM, Zilz N, Beazer-Barclay Y, et al. Apc mutations occur early during colorectal tumorigenesis. Nature 1992;359:235-7.

19 Piazza GA, Kulchak Rahm AL, Krutzysch M, et al. Anti-neoplastic drugs sulindac sulfide and sulfone inhibit cell growth by inducing apoptosis. Cancer Res 1995;55:3110-16.

20 Pasricha PJ, Bedi A, O'Connor K, et al. The effects of sulindac on colorectal proliferation and apoptosis in familial adenomatous polyposis. Gastroenterology 1995;109:994-8.

21 Shiff S J, Qiao L, Tsai L, et al. Sulindac sulfide, an aspirin-like compound, inhibits proliferation, causes cell cycle quiescence, and induces apoptosis in HT-29 colon adenocarcinoma cells. F Clin Invest 1995;96:491-503.

22 Tsuji M, Dubois RN. Alterations in cellular adhesion and apoptosis in epithelial cells over-expressing prostaglandin endoperoxide synthase 2. Cell 1995;83:493-501.

23 Elder DJE, Hague A, Hicks DJ, et al. Differential growth inhibition by the aspirin metabolite salicylate in human colorectal tumour cell lines: enhanced apoptosis in carcinoma and in vitro-transformed adenoma relative to adenoma cell lines. Cancer Res 1996;56:2273-6.

24 Ladenheim J, Garcia G, Titzor D, et al. Effect of sulindac on sporadic colonic polyps. Gastroenterology 1995;108:1083-7.

25 Lala PK, Parhar RS, Singh P. Indomethacin therapy abrogates the prostaglandin mediated suppression of natural killer activity in tumor-bearing mice and prevents tumor metastasis. Cell Immunol 1986;99:108-18.

26 Narisawa T, Takahashi M, Masuda T, et al. Prevention of peritoneal carcinomatosis recurrence with a prostaglandin synthesis inhibitor, carcinomatosis recurrence with a prostaglandin syn
indomethacin. Gan To Kagaku Ryoho 1987;14:2496-501.

27 Schultz RM, Altorn MG. Potentiation of non-specific immunotherapy of experimental lung metastases by indomethacin. F Immunopharmacol 1983; 5:277-80

28 Weppelmann B, Monkemeier D. The influence of prostaglandin antagonists on radiation therapy of carcinoma of the cervix. Gynecol Oncol 1984;17:196-9.

29 Langman MJS, Weil J, Wainwright P, et al. Risks of bleeding peptic ulcer associated with individual non-steroidal anti-inflammatory drugs. Lancet 1994;343:1075-8

30 Silverstein FE, Graham DY, Senior JR, et al. Misoprostol reduces serious gastrointestinal complications in patients with rheumatoid arthritis receiving non-steroidal anti-inflammatory drugs. Ann Intern Med 1995;123:241-9.

31 Ehsannullah RSB, Page MC, Tildesley G, et al. Prevention of gastroduodenal damage induced by non-steroidal anti-inflammatory drugs: controlled nal damage induced by non-steroidal anti-
trial of ranitidine. $B M \mathcal{F} 1988 ; 297: 1017-21$

32 Taha A, Hudson N, Hawkey CJ, et al. Famotidine for prevention of gastric and duodenal ulcers caused by non-steroidal anti-inflammatory drugs. $N$ Engl F Med 1996;334:1435-9.

33 Jansen JBMJ, Klinkenbery-Knol EC, Meuwissen SGM, et al. Effect of longterm treatment with omeprazole on gastric acid and pepsin secretion and fasting serum gastrin and serum group $A$ and $C$ pepsinogens in patients with reflux esophagitis. Gastroenterology 1990;99:621-8.

34 Thorburn CM, Friedman GD, Orentreich N, et al. High gastrin levels increase risk for colorectal carcinoma [abstract]. Gastroenterology 1996;110: A603.

35 Freston JW, Borch K, Brand SJ, et al. Effects of hypochlorhydria and hypergastrinemia on structure and function of gastrointestinal cells. Dig Dis Sci 1995;40:50S-62S.

36 Giovannucci E, Egan KM, Hunter DJ, et al. Aspirin and the risk of colorectal cancer in women. N Engl f Med 1995;333:609-14.

37 Gann PH, Manson JE, Glynn RJ, et al. Low dose aspirin and incidence of colorectal tumours in a randomised trial. $\mathcal{F}$ Natl Cancer Inst 1993;85:1220-4.

38 Kelly JP, Kaufman DW, Jurgelon JM, et al. Risk of aspirin-associated major upper-gastrointestinal bleeding with enteric-coated or buffered product. Lancet 1996;348:1413-16.

39 Weil J, Colin Jones D, Langman MJS, et al. Prophylactic aspirin and risk of peptic ulcer bleeding. BMF 1995;310:827-30.

40 Huang ME. Use of all-trans retinoic acid in the treatment of acute promyelocytic leukaemia. Blood 1988;72:567-72.

41 Castaigne S. All trans retinoic acid as a differentiation therapy for acute promyelocytic leukaemia. Blood 1990;76:1704-9.

42 Kane KF, Langman MJS, Williams GR. Anti-proliferative reponses of two human colon cancer cell lines to vitamin D3 are differentially modified by 9-cis retinoic acid. Cancer Res 1996;56:623-32.

43 Lehmann JM. Retinoids selective for retinoid X receptor pathways. Science 1992;258:1944-6.

44 Stahelin HB, Gey KF, Eichholzer M, et al. Beta-carotene and cancer prevention: the Basel study. Am f Clin Nutr 1991;53(suppl 1):265-9S. 
45 Cahill RJ, O'Sullivan KR, Matthias PM, et al. Effects of vitamin antioxidant supplementation on cell kinetics of patients with adenomatous polyps. Gut 1993;34:963-7.

46 Paganelli GM, Biasco G, Brandi G, et al. Effect of vitamin A, C and E supplementation on rectal cell proliferation in patients with colorectal adenomas. $\mathcal{F}$ Natl Cancer Inst 1992;84:47-51.

47 Roncucci L, Di Donato P, Carati L, et al. Antioxidant vitamins or lactulose for the prevention of the recurrence of colorectal adenomas. Dis Colon Rectum 1993;36:227-34.

48 Ferraroni M, La Vecchia C, D'Avanzo B, et al. Selected micronutrient intake and the risk of colorectal cancer. Br F Cancer 1994;70:1150-5.

49 Willett WC, Hunter DJ. Vitamin A and cancers of the breast, large bowel, and prostate: epidemiologic evidence. Nutr Rev 1994;52:S53-9.

50 Greenberg ER, Baron JA, Tosteson TD, et al. A clinical trial of antioxidant vitamins to prevent colorectal adenoma. $N$ Engl f Med 1994;331:141-7.

51 Omenn GS, Goodman G, Thornquist MD, et al. Effects of combination of beta-carotene and vitamin A on lung cancer and cardiovascular disease. $N$ Engl f Med 1996;334:1150-5.

52 Hennekens $\mathrm{CH}$, Buring JE. Long term supplementation with beta-carotene on the incidence of malignant neoplasms and cardiovascular disease. $N$ Engl f Med 1996;334:1145-9.

53 The Alpha-Tocopherol, Beta-Carotene Cancer Prevention Study Group (1994). The effect of vitamin $\mathrm{E}$ and beta-carotene on the incidence of lung cancer and other cancers in male smokers. N Engl f Med 1994;330:1029-35.
Fanjul AN. Hydroxyphenyl retinamide is a highly selective activator of retinoid receptors. F Biol Chem 1996;271:23441-6.

55 PingLu X, Fanjul A, Picard N, et al. Novel retinoid-related molecules as apoptosis inducers and effective inhibitors of human lung cancer cells in vivo. Nat Med 1997;3:686-90.

56 Bunce CM, Mountford JC, French PJ, et al. Potentiation of myeloid differentiation by anti-inflammatory agents, by steroids and by retinoic acid involves a single intracellular target probably an enzyme of the aldoketoseductase family. Biochim Biophys Acta 1996;1311:189-98.

57 Bussey HJ, De Cosse JJ, Deschner EE. A randomised trial of ascorbic acid in polyposis coli. Cancer 1982;50:1434-9.

58 De Cosse JJ, Miller HH, Lesser ML. Effect of wheat fibre and vitamins C and $\mathrm{E}$ on rectal polyps in patients with familial adenomatous polyposis. $\mathcal{F}$ Natl Cancer Inst 1989;81:1290-7.

59 McKeown-Eyssen G, Holloway C, Jazmaji V, et al. A randomised trial of vitamins $\mathrm{C}$ and $\mathrm{E}$ in the prevention of recurrence of colorectal polyps. Cancer Res 1988;48:4701-5.

60 Garland CF, Shekelle RB, Barrett Connor E, et al. Dietary vitamin D and calcium and risk of colorectal cancer: a 19-year prospective study in men. Lancet 1985; ;:307-9.

61 Garland CF, Comstock GW, Garland FC, et al. Serum 25-hydroxyvitamin $\mathrm{D}$ and colon cancer: eight year prospective study. Lancet 1989;ii:1176-8.

62 Emerson JC, Weiss NS. Colorectal cancer and solar radiation. Cancer Causes Control 1992;3:95-9.

63 Belleli A, Shany S, Levy J, et al. A protective role of 1,25 dihydroxy vitamin D3 in chemically induced rat colon carcinogenesis. Carcinogenesis 1992;13. 2293

64 Sitrin MD, Halline AG, Abrahams, C, et al. Dietary calcium and vitamin D modulate 1,2 dimethylhydrazine-induced colonic carcinogenesis in the rat. Cancer Res 1991;51:5608-13.

65 Kane KF, Langman MJS, Williams GR. 1,25 dihydroxy vitamin D3 and retinoid $\mathrm{X}$ receptor expression in human colorectal neoplasms. Gut 1995;36:255-8.

66 Eisman JA, Barkla DH, Tutton PJM. Suppression of in-vivo growth of human cancer solid tumour xenografts by 1,25 dihydroxy vitamin D3. human cancer solid tumo
Cancer Res 1987;47:21-5.

67 Slater SJ, Kelly MB, Taddeo FJ, et al. Direct activation of protein kinase C by 1,25-dihydroxy Vitamin D3. F Biol Chem 1995;270:6639-43.

68 Binderup L, Latini S, Binderup E, et al. 20-epi-vitamin D3 analogues: a novel class of potent regulators of cell growth and immune responses. Biochem Pharmacol 1991;42:1569-75.

69 Binderup L, Bramme E. Effects of a novel vitamin D analogue MC903 on cell proliferation and differentiation in vitro and on calcium metabolism in vivo. Biochem Pharmacol 1988;37:889-95.

70 Wali RK, Bissonnette M, Khare S, et al. 1,25-dihydroxy-16-ene-23-yne-26, 27-hexafluorocholecalciferol, a non-calcemic analog of 1,25-dihydroxy vitamin $\mathrm{D} 3$ inhibits azoxymethane-induced colonic tumorigenesis. Cancer Res 1995;55:3050-4.

71 Kampman E, Giovannucci E, van't Veer P, et al. Calcium, Vitamin D, dairy foods, and the occurrence of colorectal adenomas among men and women in two prospective studies. Am f Epidemiol 1994;139:16-29.

72 Bostick RM, Potter JD, Sellers TA, et al. Relation of calcium, vitamin D, and dairy food intake to incidence of colon cancer among older women. The dairy food intake to incidence of colon cancer among older wo

73 Byrne PM, Freaney R, McKenna MJ. Vitamin D supplementation in the elderly: review of safety and effectiveness of different regimes. Calcified Tissue International 1995;56:518-20.

74 Reshef R, Rozen P, Fireman Z, et al. Effect of a calcium enriched diet on the colonic epithelial hyperproliferation induced by N-methyl-N-nitro-Nnitrosoguanidine in rats on a low calcium and fat diet. Cancer Res 1990;50: 1764-7. 75 Bostick RM, Potter JD, Fosdick L, et al. Calcium and colorectal epithelial
proliferation - a preliminary randomised doubled-blinded placebocontrolled clinical trial. F Natl Cancer Inst 1993;85:132-41.

76 Longnecker MP, Martin-Moreno JM, Knekt P, et al. Serum alphatocopherol concentration in relation to subsequent colorectal cancer: pooled data from five cohorts. $\mathcal{F}$ Natl Cancer Inst 1992;84:430-5.

77 Bostick RM, Potter JD, McKenzie DR, et al. Reduced risk of colon cancer with high intake of vitamin E: the Iowa Women's Health Study. Cancer Res 1993;53:4230-7.

78 Giovannucci E, Stampfer MJ, Colditz G, et al. Folate, methionine, and alcohol intake and risk of colorectal adenoma. 7 Natl Cancer Inst 1993;85:875-84.

79 Freudenheim JL, Graham S, Marshall JR, et al. Folate intake and carcinogenesis of the colon and rectum. Int F Epidemiol 1991;20:368-74.

80 Bird CL, Swendseid ME, Witte JS, et al. Red cell and plasma folate, folate consumption, and the risk of colorectal adenomatous polyps. Cancer Epidemiol Biomarkers Prev 1995;4:709-14.

81 Cravo ML, Mason JB, Dayal Y, et al. Folate deficiency enhances the development of colonic neoplasia in diphenylhydrazine-treated rats. Cancer Res 1992;52:5002-6. 81a Kim YI, Salomon RN, Graeme-Cook F, et al. Dietary folate protects against the development of macroscopic neoplasia in a dose-responsive (1996:39:732-40.

82 Bestor TH. Methylation meets acetylation. Nature 1998;393:311-12.

82a Baron JA, Sandler RS, Haile RW, et al. Folate intake, alcohol consumption, cigarette smoking and risk of colorectal adenomas. F Natl Cancer Inst 1998; 90:57-62.

83 Lashner BA. Red blood cell folate is associated with the development of dysplasia and cancer in ulcerative colitis. F Cancer Res Clin Oncol 1993;119: 549-54.

83a Welch GN, Loscalzo J. Homocysteine and atherosclerosis. N Engl f Med 1998;338:1042-50.

84 De Flora S, Astengo M, Serra D, et al. Inhibition of urethan-induced lung tumors in mice by dietary N-acetylcysteine. Cancer Lett 1986;32:235-41.

85 de Vries N, van Zandwijk N, Pastorino U, et al The Euroscan study trial. Br

f Cancer 1991;64:985-9.
86 Earnest DL, Holubec H, Wali RK, et al. Chemoprevention of azoxymethane-induced colonic carcinogenesis by supplemental dietary ursodeoxycholic acid. Cancer Res 1994;54:5071-4.

87 Rodrigues CMP, Kren BT, Steer CJ, et al. The site-specific delivery of ursodeoxycholic acid to the rat colon by sulfate conjugation. Gastroenterology 1995;109:1835-44.

88 Wali RK, Frawley BP, Hartmann S, et al. Mechanism of action of chemoprotective ursodeoxycholate in the azoxymethane model of rat colonic carcinogenesis: potential roles of protein kinase C-alpha B11 and -3. Cancer Res 1995;55:5257-64.

89 Tonneson H, Knigge U, Bulow S, et al. Effect of cimetidine on survival after gastric cancer. Lancet 1988;ii:990-2.

90 Matsumoto $\mathrm{M}$. Cimetidine and survival with colorectal cancer. Lancet 1995;346:115.

91 Adams WJ, Morris DL. Short course cimetidine and survival with colorectal cancer. Lancet 1994;344:1768-9.

92 Kumar A. Cimetidine an immuno-modulator. Ann Pharmacother 1990;24: 289-95.

93 Watson SA, Wilkinson LJ, Robertson JR, et al. Effect of histamine on the growth of human gastro-intestinal tumours: reversal by cimetidine. Gut

94 Tutton PJ, Barkla DH. Comparison of the tumour inhibiting effects of three histamine $\mathrm{H}_{2}$ antagonists. Anticancer Res 1983;3:7-10.

95 Hahm KB, Lee SI, Chung JP, et al. Comparison of immuno-modulative effects of histamine $\mathrm{H}_{2}$ receptor antagonists in gastric cancer patients focus on the lymphoblastogenesis and cytotoxicity of peripheral blood mononuclear cells. Int $\mathcal{F}$ Immunopharmacol 1994;16:9985-93.

96 Colin Jones DG, Langman MJS, Lawson DH, et al. Postmarketing surveillance of the safety of cimetidine: 10 year mortality report. Gut 1992;33:1280-4.

97 Hallissey MT, Dunn JA, Baker PG, et al. A prospective randomised trial of cimetidine therapy in gastric cancer: an interim report [abstract]. Gut 1996;37(suppl 3):A93.

98 Liu T, Mokuolo AO, Rao CV, et al. Regional chemoprevention of carcinogeninduced tumours in rat colon. Gastroenterology 1995;109:1167-72.

99 Meyskens FL, Gerner EW. Development of difluoro-methylornithine as a chemoprevention agent for the management of colon cancer. $\mathcal{F}$ Cell Biochem 1995(suppl 22):126-31.

100 Singh J, Kulkarric N, Kelloff G, et al. Modulation of azoxymethane induced mutational activation of ras proto-oncogenes by chemopreventative agents in colon carcinogenesis. Carcinogenesis 1994;15:1317-23.

101 Love RR, Carbone PP, Verma AK, et al. Randomized phase 1 chemoprevention dose-seeking study of alpha-difluoromethylornithine. Natl Cancer Inst 1993;85:732-7.

102 Rao CV, Rivenson A, Katiwalla M, et al. Chemopreventive effect of oltipraz during different stages of experimental colon carcinogenesis induced by azoxymethane in male F344 rats. Cancer Res 1993;53:2502-6.

103 O'Dwyer PJ, Szarka CE, Yao KS, et al. Modulation of gene expression in subjects at risk for colorectal cancer by the chemopreventative dithiolethione oltipraz. $\mathcal{F}$ Clin Invest 1996;98:1210-17.

104 Schwartz AG, Pashko LL. Cancer chemoprevention with the adrenocortical steroid dehydroepiandrosterone and structural analogs. $f$ Cell Biochem 1993(suppl 17G):73-9.

105 Clark LC, Hixson LJ, Combs GF Jr, et al. Plasma selenium concentration predicts the prevalence of colorectal adenomatous polyps. Cancer Epidemiol Biomarkers Prev 1993;2:41-6.

106 Reddy BS, Rivenson A, El Bayoumy K, et al. Chemoprevention of colon cancer by organoselenium compounds and impact of high- or low-fat diets. F Natl Cancer Inst 1997;89:506-12.

107 Vanden Brandt PA, Goldbohm RA, van't Veer P, et al. A prospective cohort study on toenail selenium levels and risk of gastrointestinal cancer. $\mathcal{F}$ Natl Cancer Inst 1993;85:224-9.

108 Garland M, Morris JS, Stampfer MJ, et al. Prospective study of toenail selenium levels and cancer among women. $\mathcal{F}$ Natl Cancer Inst 1995;87:497.

109 Nelson RL, Davis FG, Sutter E, et al. Serum selenium and colonic neoplastic risk. Dis Colon Rectum 1995;38:1306-10.

$110 \mathrm{Kuo}$ SM. Antiproliferative potency of structurally distinct dietary flavonoids on human colon cancer cells. Cancer Lett 1996;110:41-8.

111 Jang $M$, Cai L, Udeani GO, et al. Cancer chemopreventative activity of resveratrol, a natural product derived from grapes. Science 1997;275:218-20.

112 Singh S, Sheppard MC, Langman MJS. Sex differences in the incidence of colorectal cancer: an exploration of oestrogen and progesterone receptors. Gut 1993;34:611-15

113 Calle E, Miracle Mahill HL, et al. Estrogen replacement therapy and risk of fatal colon cancer in a prospective cohort of post menopausal women. $\mathcal{F}$ Natl Cancer Inst 1995;87:517-23.

114 Newcomb PA, Storer BE. Postmenopausal hormone use and risk of large bowel cancer. ₹ Natl Cancer Inst 1995;87:1067-71.

115 Zelen M. Are primary cancer prevention trials feasible? $\mathcal{f}$ Natl. Cancer Inst 1988;80:1442-4

116 Morson BC. Gastrointestinal pathology. Oxford: Blackwell Science, 1979

117 Winawer SJ, Zauber AG, O'Brien MJ, et al. Randomised comparison of surveillance intervals after colonoscopic removal of newly diagnosed adenomatous polyps. $N$ Engl f Med 1993;328:901-6.

118 Cali RL, Pitsch RM, Thorson AG, et al. Cumulative incidence of metachronous colorectal cancer. Dis Colon Rectum 1993;36:388-93. 